\title{
Dix ans de gestion d'un marais par le pâturage extensif; productivité comparée de troupeaux de bovins et de chevaux (marais Vernier, Eure, France)
}

\author{
T Lecomte, C Le Neveu \\ Parc naturel régional de Brotonne, 76940 Notre-Dame-de-Bliquetuit, France
}

Dans la partie tourbeuse du marais Vernier (basse vallée de Seine), la déprise agricole conduit à un enfrichement, entraînant la perte de la richesse spécifique des biocénoses. À la réserve naturelle des Mannevilles, une gestion expérimentale (pâturage extensif) a été définie (Lecomte, Le Neveu, 1986) dès 1979 (Bovins West Highland) et 1981 (chevaux Camargue) et a donné sur un plan biocénotique d'excellents résultats (Le Neveu, Lecomte, 1992). Les troupeaux, outils de gestion, procurent des données zootechniques intéressantes à publier, vu les conditions très difficiles qu'offre le marais, et le recul de l'expérience.

Les 2 espèces sont placées dans 2 enclos contigus chargés à raison de 0,77 UMB/ha pour des juments (poids moyen : $422 \mathrm{~kg}$ ), à raison de $0,5 \mathrm{UMB} / \mathrm{h}$ a pour les vaches $(386 \mathrm{~kg})$, et il y a retrait des jeunes excédentaires. La monte se fait en liberté, il n'y a pas de complémentation ni de vermifugation. Sur 10 ans (127 annéesjuments) et sur 12 ans (101 annéesvaches) sont nés 117 poulains (poids moyen au sevrage $196 \mathrm{~kg}, 46 \%$ du poids moyen de la mère) et 81 veaux (136 kg, $35 \%$ du poids de la mère) conférant aux juments un taux de naissance $(92,1 \%)$ supérieur à celui des vaches $(80,2 \%)$. La mortalité des poulains est plus forte $(13,7 \%)$ que celle des veaux $(9,8 \%)$, et s'exerce de façon constante de la naissance au sevrage, au contraire des veaux (mortalité nulle après le 1er mois). Au sevrage, la productivité globale des 2 espèces est alors plus proche : $79,5 \%$ (chevaux) et $72,3 \%$ (bovins). Le poids supérieur des poulains confère une productivité annuelle plus grande des juments (156 kg/femelle) que des vaches $(98 \mathrm{~kg})$. Cependant, les juments plus lourdes et monogastriques occupent plus d'espace, faisant que, globablement, la productivité moyenne en jeunes des 2 enclos est très comparable : $78 \mathrm{~kg} / \mathrm{ha}$ pour les chevaux et $76 \mathrm{~kg} / \mathrm{ha}$ pour les bovins.

En conclusion, un choix correct de races et de pratique de gestion autorise la survie de troupeaux qui, placés en conditions difficiles et en absence d'intrants, ont une productivité conséquente. Elle demeure très comparable entre les 2 espèces et ce sont plutôt d'autres paramètres - coût d'installation, débouchés, impact sur le milieu - qui permettront un éventuel choix.

Lecomte T, Le Neveu C (1986) Thèses de doctorat, université de Rouen, $630 p$

Le Neveu C, Lecomte T (1992) CEREOPA, $18^{e}$ Journée d'étude, 28-36 